\title{
Traces of palaeoseismic activity in Lednika Cave, Western Rhodopes Mts, South Bulgaria
}

\section{Следи от палеосеизмична активност в пещерата Ледника, Западни Родопи, Южна България}

\author{
Konstantin Kostov ${ }^{1}$, Tzvetan Ostromsky ${ }^{2}$ \\ Константин Костов ${ }^{1}$, Цветан Остромски ${ }^{2}$
}

${ }^{1}$ Geological Institute, Bulgarian Academy of Sciences, Acad. G. Bonchev St., 24, 1113 Sofia; E-mail: kskostov@geology.bas.bg

${ }^{2}$ Institute of Information and Communication Technologies, Bulgarian Academy of Sciences, Acad. G. Bonchev St., 2 ,

1113 Sofia; E-mail: ceco@parallel.bas.bg

\begin{abstract}
The caves are medium favorable for preservation of palaeoclimatic and palaeoseismic records. The deformed speleothems are accepted as a modern and useful tool for the prehistoric seismicity reconstruction. The aim of this short communication is to report the presence of deformed deposits in a newly discovered cave in South Bulgaria. Fallen, displaced and broken speleothems were found in the Lednika Cave. This $1287 \mathrm{~m}$ long cave is located near the Lepenitsa Cave, where such deformations are well described in the literature.
\end{abstract}

Keywords: paleoseismicity, speleothems, Lednika Cave, Rhodopes, Bulgaria.

\section{Въведение}

Карстовите пещери са относително консервативна среда, характеризираща се с почти постоянна годишна температура и сведено до минимум въздействие на екзогенни геоморфоложки процеси като изветряне и дефлация. Пещерните седименти се възприемат като един от най-прецизните и надеждни записи на палеоклиматични и палеосеизмични събития през кватернера (Shanov, Kostov, 2015). Анализът и датирането на силни сеизмотектонски събития в пещерите е от съществена полза за изследване режима на повтаряемост на земетресенията, а оттук и в предсказателен аспект.

В нашата страна началото на системно изучаване на следи от палеоземетресения в подземни карстови форми бе поставено от колектива на секция „Геология на земетресенията“ към Геологическия институт при БАН в края на миналия век. Първата пещера, в която бяха извършени задълбочени и съвременни палеосеизмични изследвания в България, бе Лепеница в землището на гр. Ракитово в Западните Родопи
(Shanov et al., 1998, 2001; Kostov et al., 2000). Целта на настоящето предварително съобщение е да докладва документираните индикации за въздействието на силни земетресения върху отложенията в новооткрита голяма пещера в същия карстов район.

\section{Методика}

Комплексният методически апарат за палеосеизмични проучвания в карстови пещери е въведен и описан в детайли от Shanov \& Kostov (2015). Той включва техники от редица съвременни методи на геологията, геоморфологията, инженерната сеизмология, геофизиката и ядрената геохронология, като обобщава и систематизира опита на отделни изследвания от България и света. Основа на методиката е описанието, измерването и статистическия анализ на дислоцирани, деформирани и разрушени вторични пещерни образувания (сталагмити, сталактони и сталактити). Наличието на предпочитана посока на деформациите предполага косеизмичния им произход. Чрез вземане на проби за U/Th дати- 
ране на наслагите е възможно да се определи времевия интервал на събитието, предизвикало деформациите.

За извършване на коректни палеосеизмоложки изследвания е необходимо изучаваната пещера (или нейни участъци) да са добре защитени от негативна антропогенна намеса - т.е. да са труднодостъпни и непосещавани. Пещерата Ледника е оптимален вариант за такива проучвания в международен мащаб - открита е едва преди две години и е посетена от малко на брой опитни изследователи.

\section{Пещерата Ледника: местоположение, морфология и индикатори за палеосеизмична активност}

През 2019 г. пещерняци от гр. Ракитово, водени от опитния спелеолог Стойчо Зарев, откриват голяма и красива пещера в съседство с пещерата Лепеница. Входът е отворен след разкопаване на тясна цепнатина в нисък скален венец до пътя гр. Ракитово-Лепеница. Данните за наличието на тектонски деформации в пещерата бяха лю- безно предоставени от Ст. Зарев - председател на местния пещерен клуб.

Ледника е водна пещера, разположена в северната част на Баташката планина, Западни Родопи. Входът се намира на десния бряг на p. Чукура и отстои на около 7 кm Ю3 от гр. Ракитово и на 1,2 km ЮИ от пещерата Лепеница - защитена природна забележителност от 1963 г. Образувана е в мрамори, както и повечето карстови форми в Родопите. Пещерата Ледника е в един от сеизмично активните региони на България. През 20-ти век са известни две силни земетресения. През 1905 г. е усетено земетресение с магнитуд $M_{\mathrm{s}}=4,2$, а на 3 ноември 1977 г. е регистрирано Велинградското земетресение с $\mathrm{M}_{\mathrm{s}}=5,3$, последвано от поредица афтьршокове.

Пещерата се състои от входни вертикални участъци с дълбочина 15 m и хоризонтални галерии. Картираната дължина след експедиции на Българското пещерно дружество-клон Ракитово с участие на пещерните клубове „Под Ръбъ“ (с. Церово), „Пълдин“ (Пловдив) и „Стрешеро“ (Враца) е 1287 m. Пещерата е недоизследвана. В участьците на пресичане на пукнатините, по

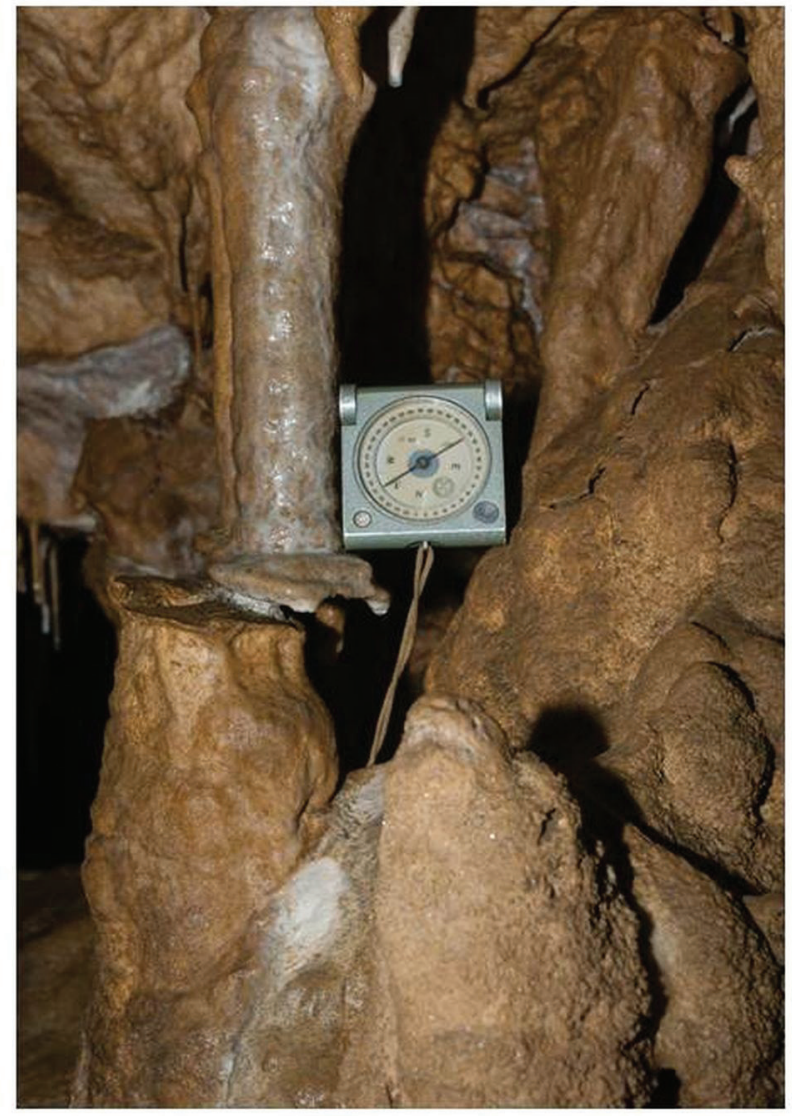

A

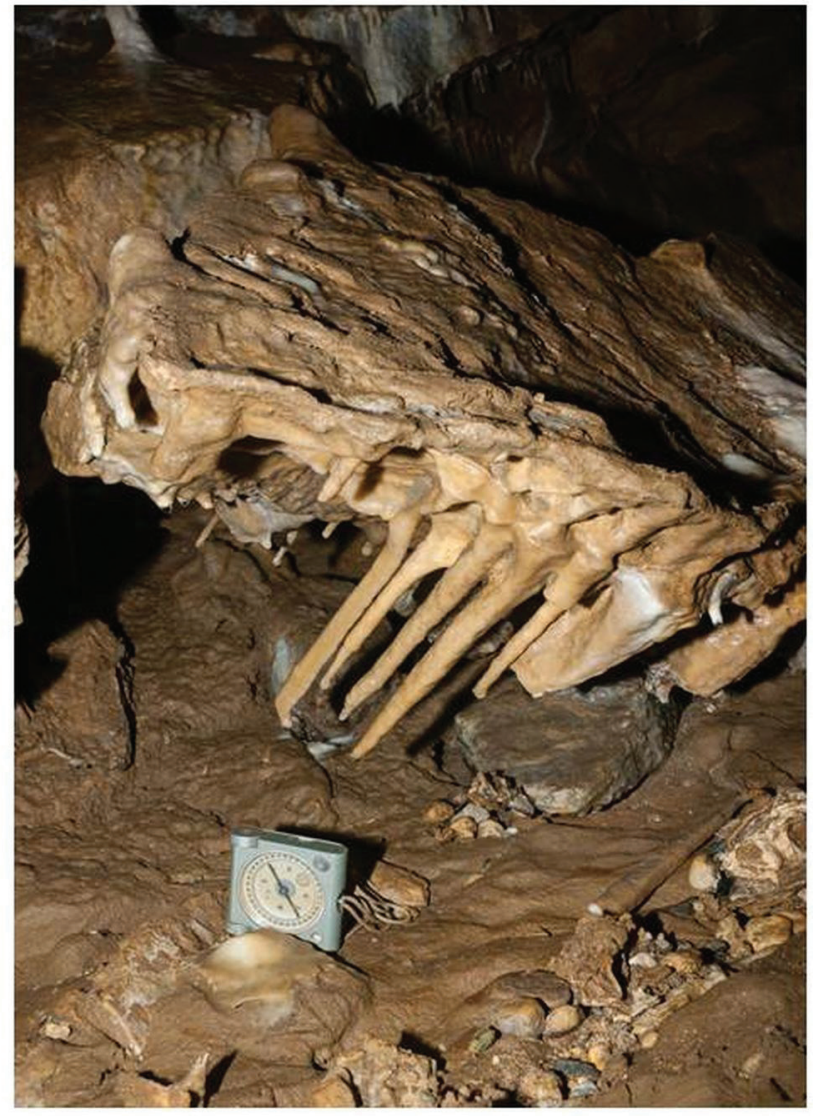

B

Фиг. 1. Деформации на вторични пещерни образувания в пещерата Ледника: $A$ - дислоциран сталактон с амплитуда на преместването $6 \mathrm{~cm} ; B$ - счупена масивна калцитна кора 
които е образувана пещерата, са формирани три зали. Наличието на подземна река в значителни части от пещерата обуславя ниската температура на въздуха - между 3,5 и $8{ }^{\circ} \mathrm{C}$ (непубликувани данни). Общата денивелация на пещерата Ледника е $47 \mathrm{~m}$. Пещерните отложения са представени от флувиални глинести наслаги, детритус и разнообразни и атрактивни вторични пещерни образувания (спелеотеми).

В пещерата са установени някои емблематични индикатори за сеизмотектонски ефект върху пещерните отложения (фиг. 1), като отворена пукнатина, срязваща сталактон с преместване в посока $248^{\circ}$ на таванната част спрямо основата на сталактона. Амплитудата на дислокацията е $6 \mathrm{~cm}$ (фиг. 1А). Отцепена и повалена масивна калцитна кора с образувани конусни сталактити с дължина до $40 \mathrm{~cm}$ (фиг. 1В) е друг сеизмичен феномен в Ледника. Документирани са и скални плочи със сталактити, обрушени от тавана и с вертикално положение спрямо пода. Върхът на плочите е припокрит с калцитни наслаги на пода, което предполага относителната старост на деформациите.

Измерването на ориентацията на описаните няколко аномалии съвпада със статистическия анализ на 67 деформации в близката пещера Лепеница (дължина 1920 m) - предпочитаната посока е север, където е и епицентърьт на известните по-силни земетресения в района гр. Велинград.

\section{Заключение}

Изследванията на палеосеизмични деформации в практически незасегнати от антропогенна намеса карстови кухини са епизодични в световен мащаб (Gilli, 2005). Рядкост са и проучванията в съседни пещери - за да бъдат проведени, необходимо е наличие на значително количество вторични образувания, което не се случва често. Представената разработка съобщава за тектонски деформации в новооткрита пещера, като се потвърждават данните от изследвания преди повече от две десетилетия в съседен обект. Данни за възрастта на млади пещерни отложения в района са съобщават от Tarassova et al., (2021), но досега не е извършено U/Th датиране в пещерите на Баташка планина. Пещерата Ледника заслужава детайлно бъдещо проучване, както и абсолютна датировка на деформираните наслаги с цел изясняване палеосеизмичната обстановка в този дял на Западните Родопи.

Благодарности: настоящето изследване е извършено с помощта на двустранния проект „Палеоклиматични реконструкции с използване на пещерни отложения от Румъния и България (2018-2020)“ между БАН и Румънската академия на науките.

\section{Литература \\ References}

Gilli, E. 2005. Review on the use of natural cave speleothems as palaeoseismic or neotectonic indicators. - Comptes Rendus Geoscience, 337, 1208-1215.

Kostov, K., S. Shanov, K. Kourtev, G. Nikolov, A. Boykova, A. Benderev, 2000. Broken speleothems as indicators of palaeoseismic activity: An example from Lepenitsa Cave in the Western Rhodope Mts., South Bulgaria. - Abstracts Geological Conference, 11-13 October, Sofia, 2000, 217-218.

Shanov, S., K. Kostov. 2015. Dynamic Tectonics and Karst. Springer-Verlag, 123 p.; https://www.doi.org/10.1007/9783-662-43992-0.

Shanov, S., K. Kourtev, K. Kostov, G. Nikolov, A. Boykova, A. Benderev, 1998. Palaeoseismological traces in the Lepenitsa Cave, Velingrad District, South Bulgaria. - ProGEO98, Abstract Volume, 53-54.

Shanov, S, K. Kourtev, K. Kostov, G. Nikolov, A. Boykova, A. Benderev. 2001. Palaeoseismological traces in the Lepenitsa Cave, Velingrad district, South Bulgaria. - In: RIVIERA 2000. Revue d'analyse spatiale. Numéro special - Tectonique active et géomorphologique. Villefranche-sur-Mer, France, 151-154.

Tarassova, E., M. Tarassov, A. Zhalov, Zh. Janakieva. 2021. Morphology of secondary calcite deposits in an abandoned mine in the Western Rhodopes, Bulgaria. - Rev. Bulg. Geol. Soc., 82, 3, 34-36; https://doi.org/10.52215/rev.bgs. 2021.82.3.34. 